\title{
Resenha de Adaptações curriculares na inclusão escolar: contrastes e semelhanças entre dois países
}

\author{
Camila Elidia Messias dos Santos' (1) \\ Francisco de Assis Medeiros (1)
}

CAPELLINI, V. L. M. F. Adaptações curriculares na inclusão escolar: contrastes e semelhanças entre dois países. Curitiba: Appris, 2018.

Escrito pela professora doutora e pesquisadora em educação especial Vera Lucia Messias Fialho Capellini, o livro Adaptações curriculares na inclusão escolar: contrastes e semelhanças entre dois países foi organizado em quatro capítulos, nos quais são realizadas comparações entre as escolas do Brasil e da Espanha.

A obra é resultado de sua tese de livre-docência, defendida em 2014, parcialmente realizada na Espanha durante um período de seis meses. O estudo contou com o financiamento da Fundação de Amparo à Pesquisa do Estado de São Paulo (Fapesp) e objetivou repetir, em parte, a pesquisa desenvolvida pela autora no Brasil acerca das adaptações curriculares, visando:

- descrever como ocorrem as adaptações curriculares nas práticas educativas em uma escola espanhola;

- verificar como se dá a colaboração entre educação especial e educação comum;

- comparar os resultados encontrados na escola espanhola com os resultados da escola brasileira.

Para isso, diferentes procedimentos foram utilizados para a coleta de dados, entre eles: questionário estruturado com a equipe escolar, teste de desempenho escolar com os alunos, observação do cotidiano da escola, registros em filmagens e análise documental, além de toda a vivência registrada em diário de bordo.

$\mathrm{Na}$ apresentação do livro, a autora destaca o uso da metodologia aprendizagem cooperativa (AC), implementado em escolas de diferentes países do mundo, e levanta importantes questionamentos como: por que a educação no Brasil continua com práticas pedagógicas que não valorizam a cooperação? Por que os professores de educação especial não trabalham colaborativamente com os professores da classe comum? Por que nos cursos de formação de professores os estudantes, com raras exceções, permanecem enfileirados, fazendo-se uso de metodologias centradas exclusivamente no professor?

"Universidade Estadual Paulista “Júlio de Mesquita Filho”, Bauru, São Paulo, Brasil. 
Mais adiante, retoma a importância da AC como metodologia de ensino a ser utilizada na classe comum, pois entende que essa metodologia valoriza as diferenças e possibilita a todos aprender e a construir uma escola inclusiva. Como benefícios, é destacado que as tarefas realizadas pelas crianças se ajustam às suas capacidades, utilizam tarefas variadas que requerem níveis e habilidades diversos, as atividades são planejadas de modo que todos participem e a atividade não se encerra sem que todos tenham terminado sua parte.

No capítulo introdutório, "Educação inclusiva: educação de qualidade para todos?", a autora enfatiza que as deficiências sempre existiram e continuarão existindo e que entender o outro enquanto diferente não significa apenas aceitar que ele difere de nós, mas sim buscar alternativas para nos comunicarmos, promovendo interação e desenvolvimento coletivo. Ao longo do texto, é realizado um histórico da pessoa com deficiência - da exclusão da sociedade à democratização do ensino -, com a atualização da constituição e dos documentos seguintes que possibilitaram aos alunos o direito à escolarização preferencialmente na rede regular de ensino, com vistas a garantir o atendimento de suas necessidades sem preconceito e/ou discriminação, do nível básico ao ensino superior. No entanto, destaca-se a necessidade de reformulação de práticas educacionais hegemônicas e de construção de espaços que garantam a participação de toda a comunidade escolar para que a educação inclusiva traga resultados positivos.

No segundo capítulo, "O estudo no Brasil: a pesquisa colaborativa como abordagem para o desenvolvimento e aprimoramento de professores", é apresentada uma descrição minuciosa de como foi desenvolvida a pesquisa realizada no Brasil que visou à implementação de um programa de formação continuada em serviço por meio da pesquisa-ação colaborativa, para que fossem oferecidos à equipe escolar orientação e apoio técnico especializado para qualificação do trabalho pedagógico. Ao relatar sua experiência, levantam-se críticas relativas às pesquisas sobre inclusão que não englobem os diferentes participantes do processo, como: equipe escolar, comunidade, pais e alunos, apontando para a imprescindibilidade da relação entre todos para o sucesso escolar. A proposta teve os intuitos de compreender e superar os problemas encontrados na inclusão escolar dos alunos, principalmente daqueles com alguma deficiência no ensino comum, com o objetivo de desenvolver experiências inovadoras em conjunto com a equipe escolar a fim de beneficiar toda a escola.

O livro prossegue e no terceiro capítulo, "O estudo na Espanha: cruzando o oceano para conhecer 'velhas' metodologias de ensino", a autora fornece uma breve explanação sobre o porquê de ter escolhido a Espanha como destino. Entre os motivos, o leitor encontrará: estratégia acadêmica, amplo acesso aos sujeitos de pesquisa, a própria organização educacional do país de destino e lacunas na literatura pertinente ao estudo proposto. Há ainda uma descrição detalhada e empolgante de suas atividades didáticas na Universidade de Alcála, instituição de ensino que a recebeu no país, incluindo a cidade, o sistema de educação, as leis que fundamentam as políticas de inclusão na Espanha em seu sistema de educação público, o público atendido, com destaque para a sua heterogeneidade, a equipe gestora, entre outros aspectos importantes para a efetivação do ano letivo.

Na segunda metade do capítulo, são detalhadas as turmas e é relatado o roteiro da observação realizada pela pesquisadora nas turmas participantes de sua pesquisa. 
Esses dados são ilustrados por imagens das salas de aula e de algumas atividades feitas pelos alunos e por quadros que os organizam, para maior comodidade do leitor e clareza. Seguindo o mesmo sentido, um exemplo de prática pedagógica para cada dia observado é destacado, enriquecendo seus relatos de forma simples e objetiva. Por fim, a autora discute aquilo que foi observado com a realidade educacional local encontrada por ela, e o leitor deparará com um conteúdo denso, porém de fácil leitura e clareza.

O quarto capítulo, "Confronto entre realidades: nem tudo que reluz é ouro", encerra o livro e faz uma comparação entre as duas realidades, brasileira e espanhola, percebidas pela autora. Com base no embate entre as realidades, a pesquisadora chega a duas conclusões: é necessário que a formação dos professores no Brasil seja revista e se estreitem as relações entre a educação comum e a educação especial. Esse modo de abordar seu objeto de estudo dá peso e profundidade ao seu relato. As diferenças pontuadas por ela sobre a educação nos dois países demonstram que o Brasil tem um déficit, mas que não está estagnado no processo inclusivo, pois há algo sendo realizado para melhorar, mesmo que ainda esteja distante do adequado.

Ao finalizar o livro, é explanada a necessidade de compartilhar algumas reflexões, certezas e muitas dúvidas, as quais endossam um caminho a seguir para melhorar a educação inclusiva no Brasil e abrem um leque para pesquisadores que desejam realizar pesquisa na área, sendo o último capítulo um dos mais ricos do livro e de indispensável leitura.

\section{REFERÊNCIAS}

CAPELLINI, V. L. M. F. Adaptações curriculares na inclusão escolar: contrastes e semelhanças entre dois países. Curitiba: Appris, 2018.

\section{SOBRE OS AUTORES}

Camila Elidia Messias dos Santos é doutoranda em psicologia do desenvolvimento e aprendizagem pela Universidade Estadual Paulista "Júlio de Mesquita Filho" (UNESP).

E-mail:kmila_messias@hotmail.com

Francisco de Assis Medeiros é mestre em psicologia do desenvolvimento e aprendizagem pela Universidade Estadual Paulista "Júlio de Mesquita Filho" (UNESP).

E-mail: franciscomedeiros999@gmail.com

Recebido em 26 de fevereiro de 2020

Aprovado em 20 de maio de 2020 